\title{
Total Body Clearance by Fraction of Dose for Dose Interval Normalized by Body Mass Index
}

National Cancer Institute

\section{Source}

National Cancer Institute. Total Body Clearance by Fraction of Dose for Dose Interval Normalized by Body Mass Index. NCI Thesaurus. Code C114227.

The total body clearance for extravascular administration for dose interval based on the fraction of dose absorbed and divided by the body mass index. 